\title{
Complementary Feeding: A Critical Approach for Prevention of Malnutrition in Infants and Young Children
}

Oluwatoyin Oluwole*, Adebukola Agboola and Temiloluwa Arowosola

Department of Food Technology, Federal Institute of Industrial Research Oshodi Lagos, Nigeria

*Corresponding author: Oluwatoyin Oluwole, Department of Food Technology, Federal Institute of Industrial Research Oshodi Lagos, Nigeria, Tel: +2348033044961; Email: oluwatoyinoluwole575@yahoo.com

Received date: January 31, 2018; Accepted date: February 11, 2018; Published date: February 18, 2018

Copyright: ( 2018 Oluwole O, et al. This is an open-access article distributed under the terms of the Creative Commons Attribution License, which permits unrestricted use, distribution, and reproduction in any medium, provided the original author and source are credited.

\begin{abstract}
Malnutrition can be defined as the shortage or surplus/imbalance of energy, protein and other nutrients causing measurable detrimental effects on the body function. It is also the cellular imbalance between the supply of nutrients and energy and the body's demand for them to ensure growth. Malnutrition could be under nutrition which is characterized by stunting, wasting, underweight. It could also be over nutrition which is evidenced in overweight and obesity. Malnutrition can occur as a result of micronutrient deficiency known as hidden hunger and it could also be protein energy malnutrition which results in Kwashiorkor and Marasmus.
\end{abstract}

\section{Introduction}

According to World Health Organization (WHO) 2017 and UNICEF (2017) statistics, globally about 52 million children under 5 years of age are wasted, 17 million are severely wasted and 155 million are stunted and 41 million are overweight or obese [1]. The death rate of children under 5 years of age in low and middle income countries due to under nutrition is globally $45 \%$. These countries also have an increasing rate in overweight and obesity in children. Additionally worldwide, 8.5 million infants aged less than 6 months are wasted. Under nutrition in early infancy have been reported [2] to be a critical factor in causing impaired growth and brain development as well as mental illness in malnourished children.

In Nigeria, more than $70 \%$ of children start receiving complementary foods between 6-8 months however only about $18 \%$ of children aged 6-23 months acquire the minimum accepted diet. Most of the younger children consume low iron rich foods thus making them vulnerable to iron deficiency. In terms of infant and young children feeding practices, North East and North West geopolitical zone have a higher percentage of malnutrition compared to other zones in the country [3]. Malnutrition is a long standing serious problem in Zambia with poor micronutrient status due to daily consumption of monotonous diets which consists of one or two staples. One in three Kenyan children suffers from chronic under nutrition which results into stunting [4]. Also more than one in five children in Ghana is stunted, $37 \%$ of children in Northern Ghana is stunted with $57 \%$ of children anemic [5].

Complementary foods are foods other than breast milk or infant formula (liquids, semisolids and solids) introduced to an infant from 6 months to provide adequate nutrient. The first two years of life represent an important time window, which is thus critical for child development [6]. Adequate introduction of complementary food have been reported to prevent infectious diseases such as diarrhea and pneumonia.

It is important that the RDA is met for children from 6-23 months in order to prevent anemia and impaired cognitive development as a result of protein and micronutrient deficiencies such as minerals which include iron, zinc, calcium, magnesium, copper, iodine and molybdenum and vitamins which include Vitamin A, Vitamin C, Vitamin D, Vitamin E, Thiamin, Riboflavin, Niacin, Vitamin B6 and folate. It is also essential they meet up the daily intake of protein and the indicated micronutrients requirements based on established dietary reference intakes for each age group as given by the World Health Organization and Food and Nutrition Board, Institute of Medicine. The importance of vitamins cannot be overemphasized because they are needed for co-enzyme function of carbohydrate and amino acid while minerals are essential for skeletal development, energy production and growth and development of the brain and central nervous system.

\section{Complementary feeding as a preventive approach to malnutrition}

The introduction of nutritious complementary foods at 6 months to infants with continuous breastfeeding is a major preventive approach to malnutrition. Over the years, some of the complementary foods introduced include cereals such as maize gruel which contains little or no protein and inadequate to meet up with the recommended dietary allowance for infants, however lately some mothers now include legumes such as soya beans and other protein sources like crayfish, groundnut etc. to complementary meals thus improving the quality of the diet.

The first major preventive approach to Malnutrition is through food fortification, fortified foods should be introduced to infants so as to meet up with their RDA. Major food fortification interventions include the addition of vitamin A, iron, zinc and iodine to food products such as cereals, flours and milk. Multiple micronutrient powder (MNP) interventions has been introduced in about 22 countries in Asia and Latin America to improve complementary food and this has reached over 12 million children as at 2010 [7].

Additionally, creating more awareness to mothers and care givers on the importance of food diversity and the basic nutritional needs of infants will equally help them to take adequate steps in ensuring every meal is balanced and highly nutritious. Also, foods should be 
Citation: Oluwole O, Agboola A, Arowosola T (2018) Complementary Feeding: A Critical Approach for Prevention of Malnutrition in Infants and Young Children. J Nutr Disorders Ther 8: 225. doi:10.4172/2161-0509.1000225

Page 2 of 2

introduced gradually that is one at a time in order to easily detect food intolerance and allergies amongst children [8].

Lastly, complementary foods must be prepared in a safe, healthy and hygienic manner to minimize infection amongst infants [9].

\section{Conclusion}

Affordable, nutritious complementary food should be developed and made available to mothers in different countries using appropriate processing and combination strategy with or without fortification of indigenous food crops in each country based on the recommended dietary allowance of infants as given by the World Health Organization. This should however complement the breast feeding of the infants as they attain 6 months of age. This will eventually help in ensuring improved nutrition and food security among infants globally and the number of malnourished infants will be greatly reduced globally especially in the low income countries.

\section{References}

1. Eichler K, Wieser S, Rüthemann I, Brügger U (2012) Effects of micronutrient fortified milk and cereal food for infants and children: a systematic review. BMC Public Health 12: 506.
2. FAO/WHO (2001) Human Vitamin and Mineral Requirements. Food and Nutrition Division, FAO, Rome.

3. Mwangome MK, Fegan G, Prencice M, BerkleyA (2014) Maternal perception of malnutrition among infants using verbal and pictorial methods in Kenya. Public Health Nutrition 18: 869-876.

4. National Nutrition and Health Survey (NNHS) (2015) Report on The Nutrition and Health Situation of Nigeria. National Bureau of Statistics.

5. https://www.unicef.org/nutrition/

6. UNICEF (2013) Improving child nutrition: The achievable imperative for global progress.

7. UNICEF (2012) Improving child nutrition: The achievable imperative for global progress.

8. World Health Organization (WHO) (2017) Malnutrition fact sheet.

9. WHO (2007) WHO Global Database on Child Growth and Malnutrition. Department of Nutrition for Health and Development (NHD), Geneva, Switzerland. 